\title{
Temporal changes in the internal stresses and pore pressures in a large-scale submarine mass transport deposit
}

\author{
Makoto Otsubo $^{1^{*}} \mathbb{D}$, Hajime Naruse ${ }^{2}$ and Ayumu Miyakawa ${ }^{1}$
}

\begin{abstract}
We examined the temporal changes in the internal stresses and pore fluid pressures of a submarine mass transport deposit (MTD) in the Akkeshi Formation of the Upper Cretaceous-Paleocene Nemuro Group, eastern Hokkaido Island, Japan. We first analyzed previous paleostress field results from meso-scale faults in the MTD blocks, which indicated two phases during the evolution of the debris flow: phase I, radial spreading of the flow body during downslope movement; phase II, the flow body underwent compression during deposition on the basin plain. We also estimated the pore fluid pressure ratio from the fault orientation distribution. There was a large increase in the pore fluid pressure ratio during the transition from phase I to phase II that continued to rise during the initial stage of phase II and then decreased in its latter stages, whereas the maximum horizontal compressive stress increased throughout phase II. This variation in pore fluid pressure relates to the dynamics and evolution of the debris flow, where the clasts in the central part of the flow were supported by the excess pore pressure due to the compression of the debris flow as the flow head decelerated. Although pore fluid pressure plays a critical role in the dynamics of debris flows, there was no previous methodology to quantify both the stress fields and pore fluid pressures in large debris flows and their resultant MTDs. Our results implemented for outcrop studies imply that meso-scale faults in MTDs can provide clues to better understand these paleoflow mechanisms.
\end{abstract}

Keywords: Stress, Meso-scale fault, Mass transport, Debris flow, Landslide, Subduction zone

\section{Introduction}

Mass transport deposits (MTDs) are the major components of depositional systems in deep-sea environments. For instance, when a large trench-type earthquake occurs in a subduction zone, it has the potential to initiate a large submarine mass transport process, which can in turn generate a hazardous tsunami (e.g., Gennesseaux et al. 1980; Ward 2001; Harbitz et al. 2006; Ogata et al. 2012; Festa et al. 2016). Understanding the development of MTDs is therefore an important goal for landslide hazard mitigation (e.g., Morgan et al. 2009). The concept of mass transport deposits contains a broad spectrum of depositional facies, including undeformed slide blocks facies, slump facies composed of folded and boudinaged successions, and debris flow facies characterized by

\footnotetext{
* Correspondence: otsubo-m@aist.go.jp

'Geological Survey of Japan, AIST, AIST Tsukuba Central 7, Higashi-1-1-1,

Tsukuba, Ibaraki 305-8567, Japan

Full list of author information is available at the end of the article
}

block-in-matrix structures. Among these MTD facies, this study aims to understand the formative processes of the debris-flow type facies, focusing on a role of excess pore pressure in the flow. Various field observations of modern examples and outcrops have suggested that fluid overpressure represents the most significant mechanism to account for the long run-out and the high velocity of mass transport events (e.g., Canals et al. 2004). Here, we try to measure the extent of this excess pore pressure from outcrops by quantitative textural analysis.

As described above, the behavior of debris flow sediments can be largely controlled by their excess pore pressures (e.g., Iverson 1997; Ilstad et al. 2004a, 2004b; D'Agostino et al. 2013). For instance, the experiments of Iverson et al. (2011) indicated that the acceleration of a debris flow only occurs when there is a positive feedback between overpressure in the debris flow and the entrainment of basal sediment. Excess pore pressure helps to maintain the suspension of sediment in the debris flow, 
which can then scour the bed and reduce basal friction (Major and Iverson 1999). However, many approaches that model the behavior of debris flow sediments only adopt the simple viscoplastic (Bingham) fluid approximation with a constant pore pressure (e.g., Rickenmann et al. 2006). It is therefore necessary to examine the validity of applying this approximation to observed submarine debris flow processes, particularly since the relationships between pore pressure changes and fluid-flow behavior in debris flows are unclear.

Here, we focus on the fluid-driven processes of a submarine MTD, which are related to both its flow dynamics and deformation processes. Faulting is generally attributed to overpressurization of the fault plane (e.g., Nur and Booker 1972; Sibson 2007). Previous studies have indicated that a zone of high pore fluid pressure is an important factor in the activation of faults, owing to the resultant reduction in frictional strength, which in turn leads to an instability on the fault plane (Terzaghi and Peck 1967; Rice 1992; Ogata et al. 2014a). Although basal shear stress and pore fluid pressure measurements have been made in
MTDs (e.g., Iverson 1997; Ilstad et al. 2004a, 2004b; D'Agostino et al. 2013), it is difficult to directly measure pore fluid pressures. Previous studies have therefore employed stress tensor inversions to reconstruct the paleostresses within gravitational slope failures (e.g., Husein et al. 2010; Naruse and Otsubo 2011a; Baroň et al. 2013, 2017).

Naruse and Otsubo (2011a) documented the internal structure of a submarine MTD in the Akkeshi Formation of the central section of the Upper CretaceousPaleocene Nemuro Group, eastern Hokkaido Island, northern Japan (Figs. 1 and 2). Paleostress analysis of meso-scale faults (Yamaji 2000; Otsubo and Yamaji 2006) within this large-scale MTD revealed that the evolution of the debris flow was defined by two phases: (1) an extensional stress regime due to radial spreading of the debris flow during downslope movement (phase I) and (2) a compressional stress regime during deposition of the debris on the basin plain (phase II) (Fig. 2c; Naruse and Otsubo 2011a).

Here, we examine the temporal changes in the internal stresses and pore fluid pressures in the above-
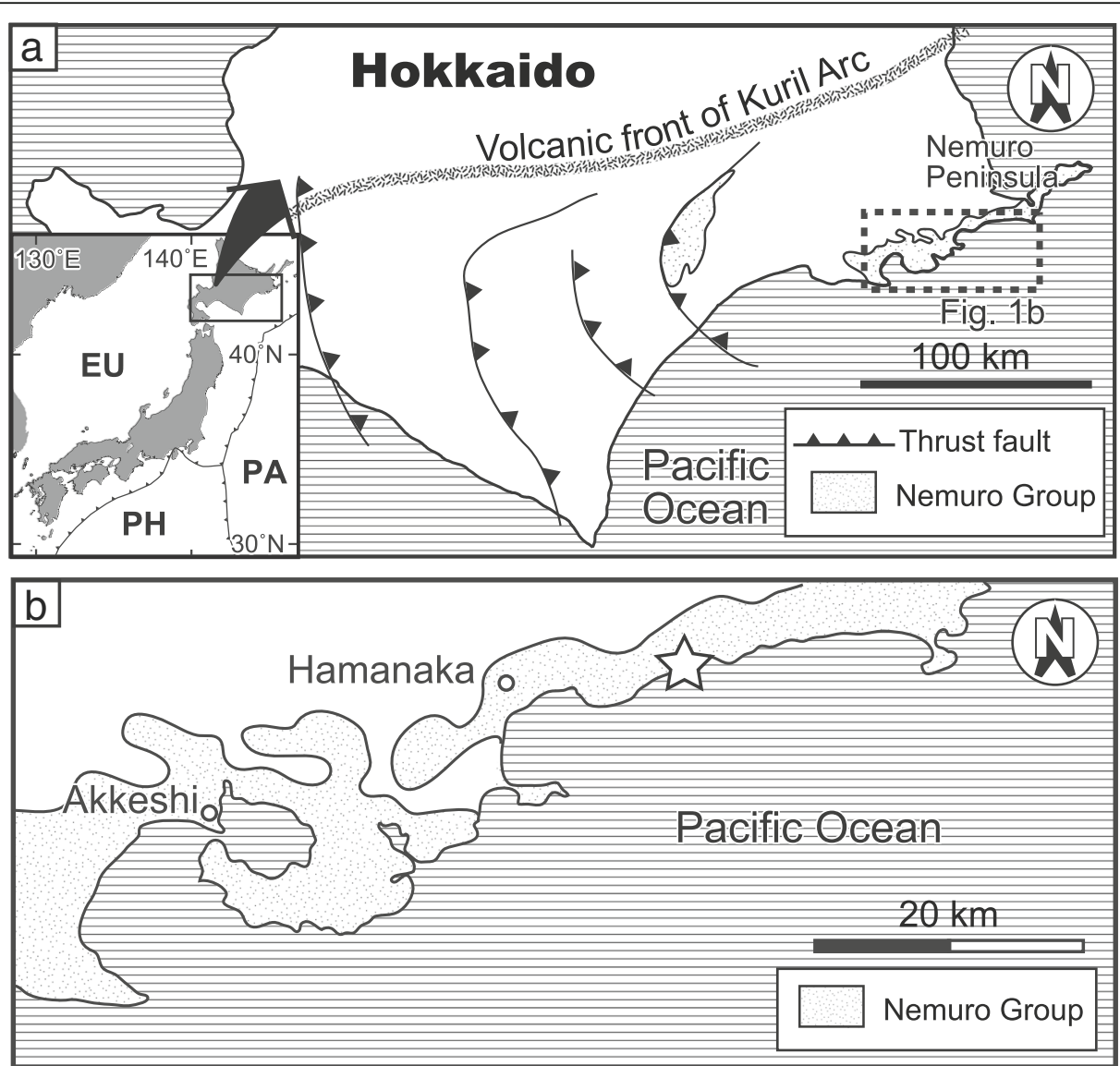

Fig. 1 Geological setting of the study area (modified from Naruse 2003). a Distribution of the Nemuro Group. b Location of the study area. Star indicates the coastal outcrop. Inset map: EU, Eurasian Plate. PA, Pacific Plate. PH, Philippine Sea Plate 


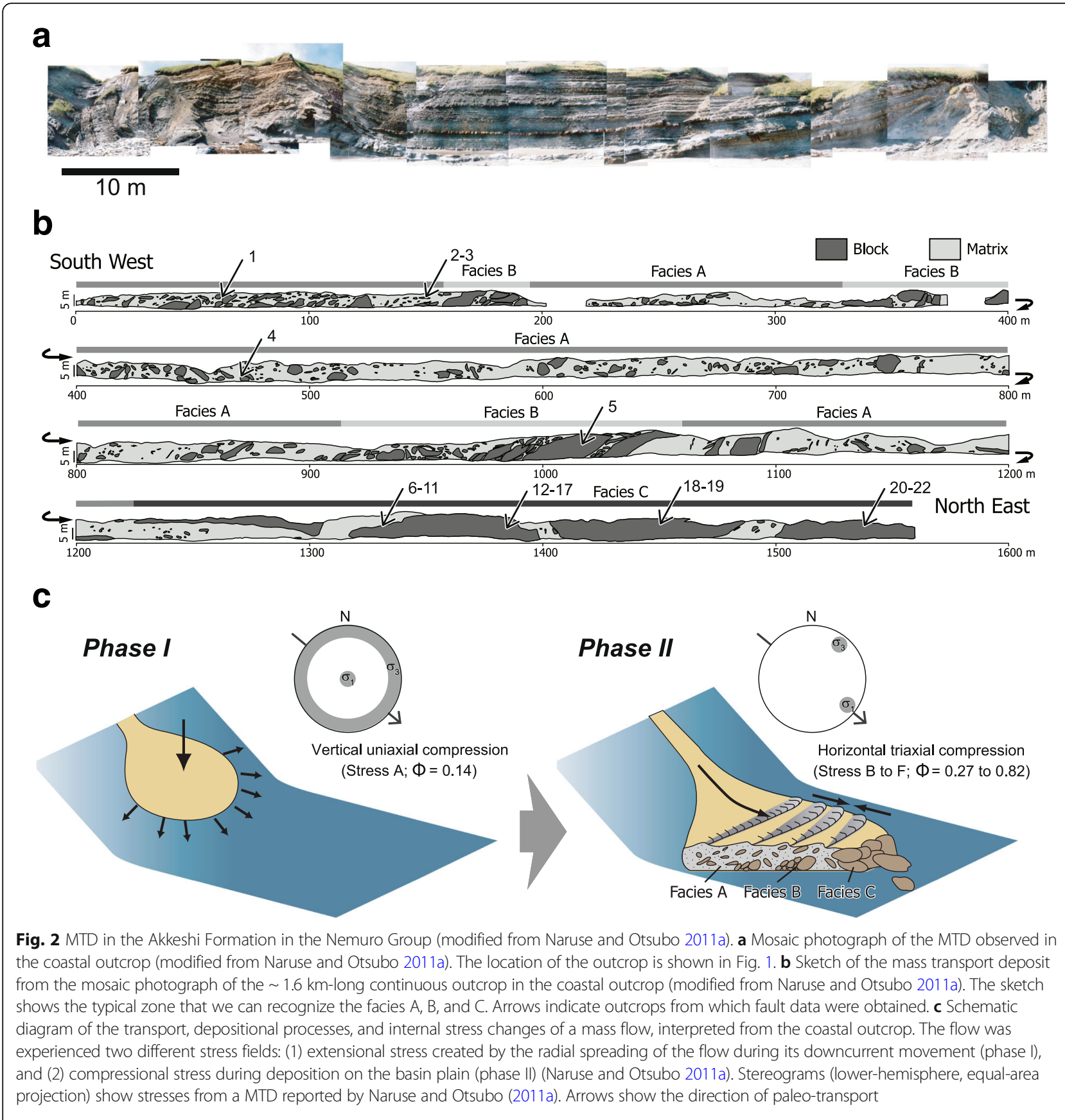

mentioned submarine MTD using the relationships between its principal stress axes and fault plane attitudes. We first introduce the internal structures and stresses in the submarine MTD. Secondary, we explain how to estimate the pore fluid pressure ratio. Thirdly, we then estimate the pore fluid pressure ratio in this submarine MTD. Finally, we conclude by discussing its dynamic processes. On the internal structures and stresses in the submarine MTD in the Akkeshi Formation, we introduce the results by Naruse and Otsubo (2011a).

\section{Geological background}

The submarine MTD in the Akkeshi Formation is from the central section of the Upper Cretaceous-Paleocene Nemuro Group in the southern Nemuro Peninsula, eastern Hokkaido Island, Japan (Fig. 1), and is interpreted to have been deposited in the fore-arc basin of the Kuril Arc (Kiminami 1983). The Nemuro Group is composed of the Nokkamappu, Otadai, Monshizu, Hamanaka, Akkeshi, and Kiritappu formations, in ascending order, and is unconformably overlain by the Eocene Urahoro 
Group. The Nemuro Group is composed of submarine fan deposits that contain hemipelagic mudstone, as well as turbidites and submarine slump deposits (Kiminami 1978; Naruse 2003). The Akkeshi Formation has been interpreted as a series of submarine channel-levee complexes with large-scale MTDs (Naruse 2003).

Here, we analyze a coastal outcrop that shows a single continuous MTD bed over a distance of $>1600 \mathrm{~m}$ (Naruse and Otsubo 2011a). Although the upper and lower boundaries are not exposed, the outcrop extends parallel to the strike of the bed and the paleo-transport directions (from northwest to southeast), such that lateral variations in the bed can be observed at nearly the same horizon. The MTD in this outcrop is subdivided into three lithofacies based on the size and spatial arrangement of accumulated blocks (Fig. 2; Naruse and Otsubo 2011a): Facies A consists of relatively small blocks that are supported by a matrix of gravelly mudstone, facies B contains clast-supported, moderate-sized blocks, and facies $\mathrm{C}$ is composed mainly of large (up to $100 \mathrm{~m}$ long) blocks.
Facies A and B occur primarily toward the proximal end of the outcrop, while facies $\mathrm{C}$ occurs only at the distal end.

\section{Syn-sedimentary stress analysis of the mass transport deposits}

Naruse and Otsubo (2011a) analyzed 22 syn-sedimentary meso-scale faults in this submarine MTD and assessed the associated stress fields during the evolution of the debris flow (Table 1). Here, we briefly summarize the results of their analysis. The observed sedimentary blocks in the MTD are generally deformed. The small blocks $(<5 \mathrm{~m}$ in diameter) commonly exhibit heavy deformation in the form of slump folding, and the larger blocks $(\sim 5-100 \mathrm{~m})$ frequently contain small internal faults (Naruse and Otsubo 2011a). The small faults in the MTD blocks do not extend into the flow matrix, suggesting a syn-sedimentary origin. Naruse and Otsubo (2011a) measured the strike and dip of these small faults with the slickensides on the fault planes (Fig. 3). NW-SE and NNW-SSW trending meso-scale faults are commonly

Table 1 Fault-slip dataset of the meso-scale faults obtained by Naruse and Otsubo (2011a) and misfit angles on the meso-scale faults. When a stress with a misfit of $<30^{\circ}$ is judged to be compatible (e.g., Nemcok and Lisle 1995), then stresses A, C, D, and F can explain slip vectors on 20 faults (excluding the data for faults 4 and 7). This result indicates that only stresses $A, C, D$, and $F$ can be adopted as the optimum solution in this study. In other words, stresses B and E are not needed to explain the data

\begin{tabular}{|c|c|c|c|c|c|c|c|c|c|c|}
\hline \multirow[t]{2}{*}{ No. } & \multicolumn{4}{|l|}{ Faults } & \multicolumn{6}{|c|}{ Misfit angle $\left(^{\circ}\right)$} \\
\hline & Strike $\left(^{\circ}\right)$ & $\operatorname{Dip}\left(^{\circ}\right)$ & Rake $\left(^{\circ}\right)$ & Sense & Stress A & Stress B & Stress C & Stress D & Stress $\mathrm{E}$ & Stress F \\
\hline 1 & $\mathrm{~N} 23 \mathrm{~W}$ & 745 & R85E & $\mathrm{N}$ & 2 & 3.3 & 93.5 & 146.2 & 149.4 & 3.6 \\
\hline 2 & N24W & 625 & R80E & $\mathrm{N}$ & 2.3 & 2.3 & 90.2 & 140.7 & 117.2 & 34.6 \\
\hline 3 & N34W & $48 \mathrm{~S}$ & R90W & $\mathrm{N}$ & 8.2 & 25.2 & 95.8 & 172.7 & 122.3 & 144.2 \\
\hline 4 & N14W & 885 & R13W & $\mathrm{N}$ & 92.4 & 91.3 & 164.7 & 142.2 & 31.9 & 101.5 \\
\hline 5 & $\mathrm{~N} 40 \mathrm{E}$ & $68 \mathrm{~N}$ & R74E & $\mathrm{R}$ & 156.8 & 146.5 & 13.3 & 9.4 & 136.9 & 34.7 \\
\hline 6 & N18W & 645 & R87E & $\mathrm{N}$ & 5.8 & 12.3 & 97.4 & 141.7 & 110.8 & 6.8 \\
\hline 7 & N30W & 805 & R85E & $\mathrm{N}$ & 2.3 & 4.9 & 97.2 & 155.4 & 164.9 & 0.3 \\
\hline 8 & N45W & $72 \mathrm{~N}$ & R73E & $\mathrm{N}$ & 1.3 & 120.7 & 8 & 19.3 & 65.5 & 161.8 \\
\hline 9 & N50W & $66 \mathrm{~S}$ & R86E & N & 3.4 & 14.5 & 131.1 & 155.1 & 151.4 & 32.3 \\
\hline 10 & N16W & $40 S$ & R25W & $\mathrm{R}$ & 102.9 & 41.9 & 10 & 3.2 & 2.2 & 92.6 \\
\hline 11 & N4E & $40 \mathrm{~N}$ & R16E & $\mathrm{R}$ & 93.4 & 8.3 & 15.6 & 17.7 & 7 & 104.4 \\
\hline 12 & N23W & 685 & R76E & $\mathrm{N}$ & 6.6 & 3.8 & 85.6 & 136.8 & 118.6 & 12.3 \\
\hline 13 & $\mathrm{~N} 22 \mathrm{~W}$ & $50 S$ & R52E & $\mathrm{R}$ & 151.5 & 167.9 & 116.9 & 77.7 & 100.8 & 4.3 \\
\hline 14 & N16W & 275 & R60E & $\mathrm{R}$ & 167.6 & 55.2 & 105.6 & 143.4 & 99.5 & 1.2 \\
\hline 15 & $\mathrm{~N} 12 \mathrm{E}$ & $40 \mathrm{~N}$ & R30E & $\mathrm{R}$ & 108.1 & 31.5 & 9.4 & 7.5 & 5.8 & 92.1 \\
\hline 16 & N8W & $60 S$ & R45W & $\mathrm{R}$ & 124.6 & 111.9 & 30.6 & 2.8 & 42.7 & 65.6 \\
\hline 17 & N33W & 625 & R62E & $\mathrm{R}$ & 157.7 & 157.9 & 107 & 40.1 & 68.4 & 122.6 \\
\hline 18 & N10W & $20 S$ & R2OW & $\mathrm{R}$ & 85.6 & 60.8 & 0.8 & 57.9 & 2.6 & 104 \\
\hline 19 & N68W & $58 \mathrm{~S}$ & R54E & $\mathrm{R}$ & 144.9 & 135.2 & 3.7 & 19 & 68.3 & 53.6 \\
\hline 20 & N30W & $82 \mathrm{~N}$ & R34W & $\mathrm{N}$ & 76 & 131 & 23.6 & 29.7 & 148.5 & 112.2 \\
\hline 21 & N64W & $84 \mathrm{~N}$ & R50E & $N$ & 3.6 & 91.9 & 8.1 & 5 & 27.7 & 121.9 \\
\hline 22 & $\mathrm{~N} 42 \mathrm{~W}$ & 825 & R2OW & $\mathrm{R}$ & 117.9 & 123.4 & 17 & 73.1 & 78.7 & 115.5 \\
\hline
\end{tabular}




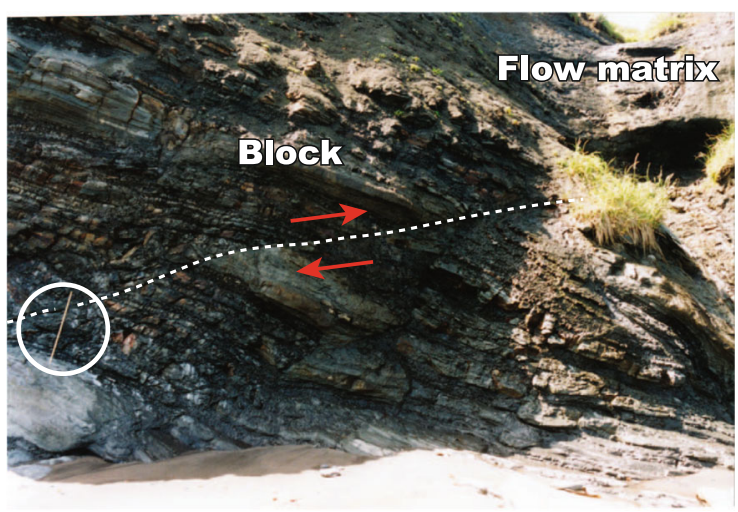

Fig. 3 Photograph of the fault observed in the coastal outcrop of the Akkeshi Formation (modified from Naruse and Otsubo 2011a). A minor deformed structure of beddings at the right end of the fault and the fact that the fault does not continue to the external matrix indicate that this fault is syn-sedimentary origin. The white circle shows a scale $(1 \mathrm{~m})$

observed in the blocks (Fig. 4). Most of the faults are reverse faults, and there are few normal faults (Fig. 4). Furthermore, six paleo-stresses (stresses A-F) were detected from the meso-scale fault data in the MTD blocks using the multiple inverse method (Yamaji 2000; Otsubo and Yamaji 2006). These stresses were classified into two groups: (1) a vertical uniaxial compression stress field with the axis of maximum compressive stress $\left(\sigma_{1}\right)$ oriented normally to bedding (stress A) and (2) horizontal triaxial compression stresses with the $\sigma_{1}$-axis oriented parallel to the paleocurrent direction (stresses B-F) (Figs. 2c and 5; Table 2; Naruse and Otsubo 2011a).

\section{Methods/Experimental}

Here, we attribute the different fault orientations to the variable pore fluid pressure regimes along the individual faults, which then allow us to estimate the pore fluid pressure ratio (Fig. 6) defined as an indicator of the pore fluid pressure regime (Hubbert and Rubey 1959). This approach can be explained using Mohr circles, where the normal and shear stresses acting on a fault of any attitude (i.e., strike and dip) within a given stress regime are described by a point on the Mohr diagram (Jaeger and Cook 1979). We assume that the shear stress $(\tau)$ acting on a fault is described by Byerlee's law, such that

$$
\tau=\mu\left(\sigma_{\mathrm{n}}-P_{\mathrm{f}}\right)
$$

where $\mu$ is the friction coefficient (usually 0.6-0.85; Byerlee $1978), \sigma_{\mathrm{n}}$ is the normal stress (with compression being positive), and $P_{\mathrm{f}}$ is the pore fluid pressure. We can therefore determine the orientation of a fault plane, along with its associated normal and shear stresses, by identifying where

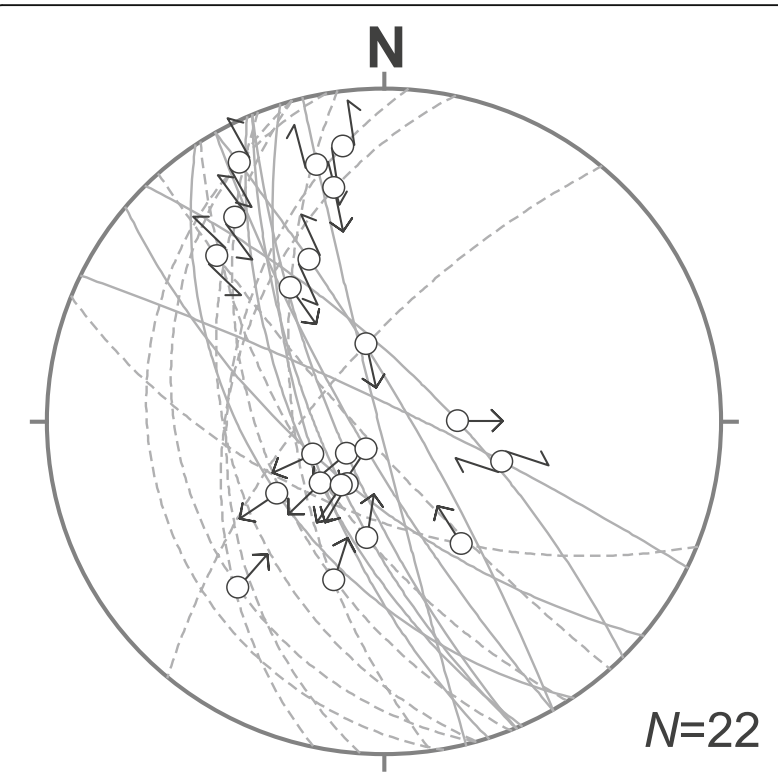

Fig. 4 Fault-slip data obtained from the coastal outcrop of the Akkeshi Formation (modified from Naruse and Otsubo 2011a). Great circles shown by lower-hemisphere, equal-angle projection represent the orientation of normal or oblique normal faults. Solid and dotted great circles represent normal or oblique normal and reverse or oblique reverse faults, respectively. Open circles on the great circles show the direction of slickenside striations on the fault planes. Arrows attached to the open circles show the sense of shear. Arrows pointing to the center of stereonet and those pointing to the opposite direction represent reverse and normal senses, respectively. Paired arrows attached to the open circles indicate a sinistral or dextral sense of shear

it is located on the Mohr diagram. Any variation in the attitudes of the faults is attributed to heterogeneities in the fault strength that are due to changes in the effective friction coefficient, which is represented by the ratio of the normal stress to shear stress on each fault (Angelier 1989). Equation 1 is therefore rewritten as

$$
\tau=\mu(1-\lambda) \sigma_{\mathrm{n}}
$$

where $\lambda$ is the pore fluid pressure ratio, which is defined by $P_{\mathrm{f}}=\lambda \sigma_{\mathrm{n}}$. This implies that $\lambda(0.0 \leq \lambda \leq 1.0)$ for a given fault plays an important role in determining $\tau$. An increase in $P_{\mathrm{f}}$ weakens the fault, such that the Coulomb failure criterion (Eq. 1) can still be satisfied if the faults are misoriented or the pore fluid is overpressurized (Terakawa et al. 2010) (Fig. 6). The normal and shear stresses acting on a given plane depend on the orientation of the plane when the principal stresses are known (Jaeger 1969), such that

$$
\sigma_{\mathrm{n}}=\sigma_{1} l^{2}+\sigma_{2} m^{2}+\sigma_{3} n^{2}
$$

and 

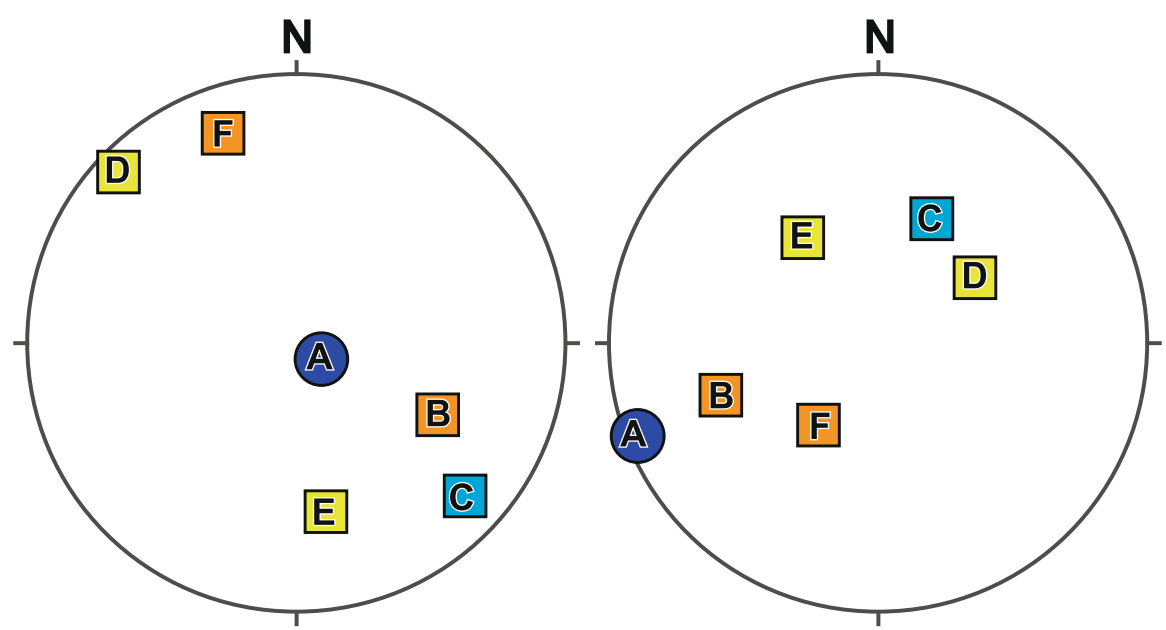

Legend

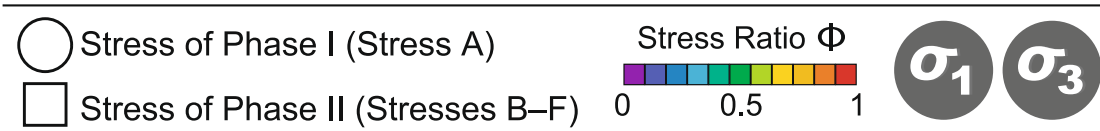

Fig. 5 Paleostresses inferred from fault-slip data obtained from the coastal outcrop of the Akkeshi Formation (modified from Naruse and Otsubo 2011 a). Lower-hemisphere, equal-area projections are shown. The symbols indicate the optimal stress solutions acquired by the multiple inversion method (Yamaji 2000; Otsubo and Yamaji 2006) and $k$-means clustering (Otsubo et al. 2006) with $k=6$. Left and right columns correspond to $\sigma_{1}$ and $\sigma_{3}$ axes, respectively. The color of the symbol represents the stress ratio, $\Phi=\left(\sigma_{2}-\sigma_{3}\right) /\left(\sigma_{1}-\sigma_{3}\right)$

$$
\tau=\sqrt{\left(\sigma_{1}-\sigma_{2}\right)^{2} l^{2} m^{2}+\left(\sigma_{2}-\sigma_{3}\right)^{2} m^{2} n^{2}+\left(\sigma_{3}-\sigma_{1}\right)^{2} l^{2} n^{2}}
$$

where $l, m$, and $n$ are the direction cosines of the normal to the plane with respect to the principal stress axes, and $\sigma_{1}, \sigma_{2}$, and $\sigma_{3}$ are the maximum, intermediate, and minimum compressive principal stresses, respectively. Here, the shear and normal stresses are normalized by the maximum shear stress $\left(\tau_{\max }\right)$. We prepared two synthetic fault planes (A and B) and a reverse faulting stress regime with the $\sigma_{1}$-axis oriented NW-SE and the subvertical $\sigma_{3}$-axis to demonstrate the model (Fig. 6a). We obtained $\lambda$ values of 0.00 and 0.42 for the fault planes $\mathrm{A}$ and $\mathrm{B}$, respectively, when we set $\mu=0.6$ (Fig. $6 \mathrm{~b}$ ). The result means that $P_{\mathrm{f}}$ for fault plane $\mathrm{B}$ is larger than that for fault plane A under same stress regime.

Table 2 List of paleostresses inferred from the meso-scale faults obtained by Naruse and Otsubo (2011a)

\begin{tabular}{|c|c|c|c|c|c|}
\hline \multirow[t]{2}{*}{ Stress } & \multicolumn{2}{|l|}{$\sigma_{1}$-axes } & \multicolumn{2}{|l|}{$\sigma_{3}$-axes } & \multirow{2}{*}{$\begin{array}{l}\text { Stress } \\
\text { ratio } \Phi\end{array}$} \\
\hline & Azimuth & Plunge & Azimuth & Plunge & \\
\hline$A$ & 130 & 81 & 248 & 4 & 0.14 \\
\hline B & 119 & 40 & 250 & 38 & 0.79 \\
\hline C & 133 & 16 & 23 & 49 & 0.27 \\
\hline D & 314 & 9 & 45 & 55 & 0.58 \\
\hline E & 171 & 36 & 323 & 51 & 0.62 \\
\hline F & 340 & 19 & 219 & 56 & 0.82 \\
\hline
\end{tabular}

\section{Results}

We examined whether all the inferred stresses are required to parameterize the 22 MTD faults, with the six sets of stresses (stresses A-F) used as candidates for determining the optimal solution to the data (Yamaji et al. 2006). We calculated the angular misfits between the slip directions that were predicted from the inferred stresses and those observed from the fault data based on the Wallace-Bott hypothesis (Wallace 1951; Bott 1959), which states that the slip vector of a fault is parallel to the resolved shear stress on the fault. Stresses A, C, D, and F can explain the slip vectors on 20 faults (not faults 4 and 7; Table 1) when we assume that a stress with a misfit of $<30^{\circ}$ is sufficient to characterize a fault (e.g., Nemcok and Lisle 1995). These results indicate that only stresses A, C, D, and F are needed to explain the data.

The faults characterized by stresses A, C, D, and F were plotted on Mohr diagrams, where we applied the Mohr circles to these 20 faults to estimate $\lambda$ (Fig. 7). All representative points (faults) for each stress are shown in the gray shaded regions in Fig. 7. The points to the left of each black dashed line in the Mohr diagrams are within the 95\% confidence limits of the fault data for every stress (Fig. 7). In this study, we define the 95\% confidence limits that represent the optimal $\lambda$ for the stresses. The $\lambda$ values for stresses $\mathrm{A}, \mathrm{C}, \mathrm{D}$, and $\mathrm{F}$ are $0.14,0.39,0.41$, and 0.71 , respectively, for $\mu=0.6$ (Fig. 7). In the case of stress $C$, we excluded fault 5 from the $\lambda$ discussions, because it lies far outside of the $95 \%$ 
a

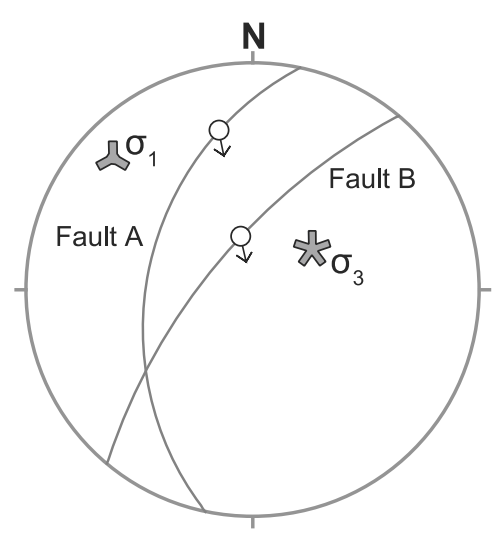

b

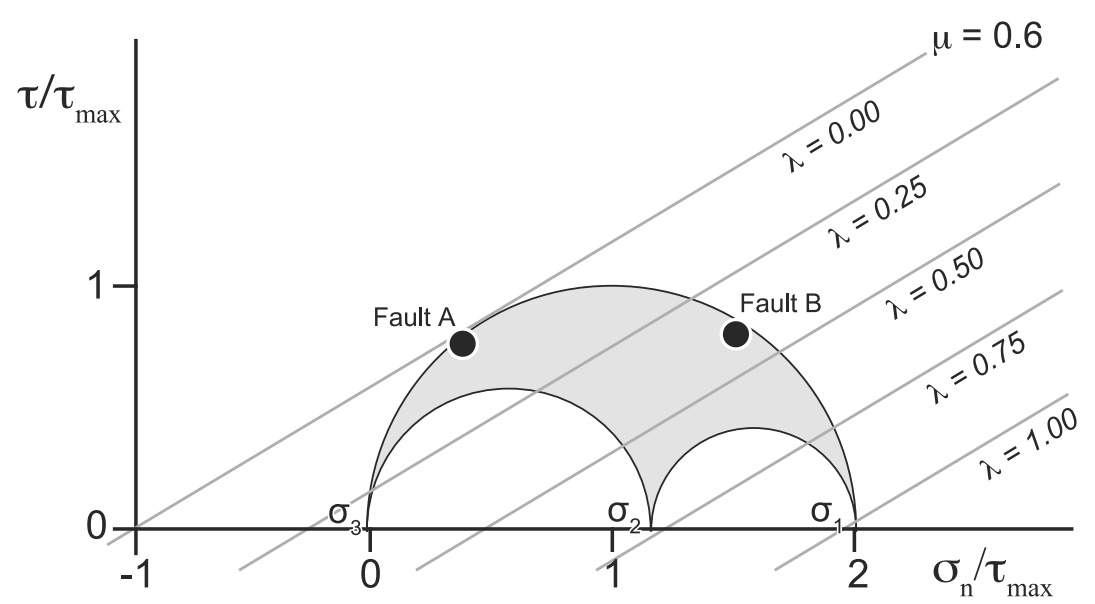

Fig. 6 Schematic illustrations to estimate pore fluid pressure ratio by using the Mohr circles. a Equal-area projection showing stress axes and fault plane with the slip direction. The stress is the reverse faulting type of stress regime. $\mathbf{b}$ Normal stress magnitudes on the fault planes calculated according to the optimal stresses. $\sigma_{1}, \sigma_{2}$, and $\sigma_{3}$ are the maximum, intermediate, and minimum compressive principal stresses, respectively. The stress ratio is 0.6 . This figure shows the Mohr's diagrams that depicts the fault data. Horizontal and vertical axes show the normal and shear stresses acting on fault planes. Gray lines show the fault strength when $\lambda=0.00,0.25,0.50,0.75$, and 1.00 . When we used a value of 0.6 for the friction coefficient $\mu$, the values of $\lambda$ for the fault planes $A$ and $B$ are 0.00 and 0.42 , respectively

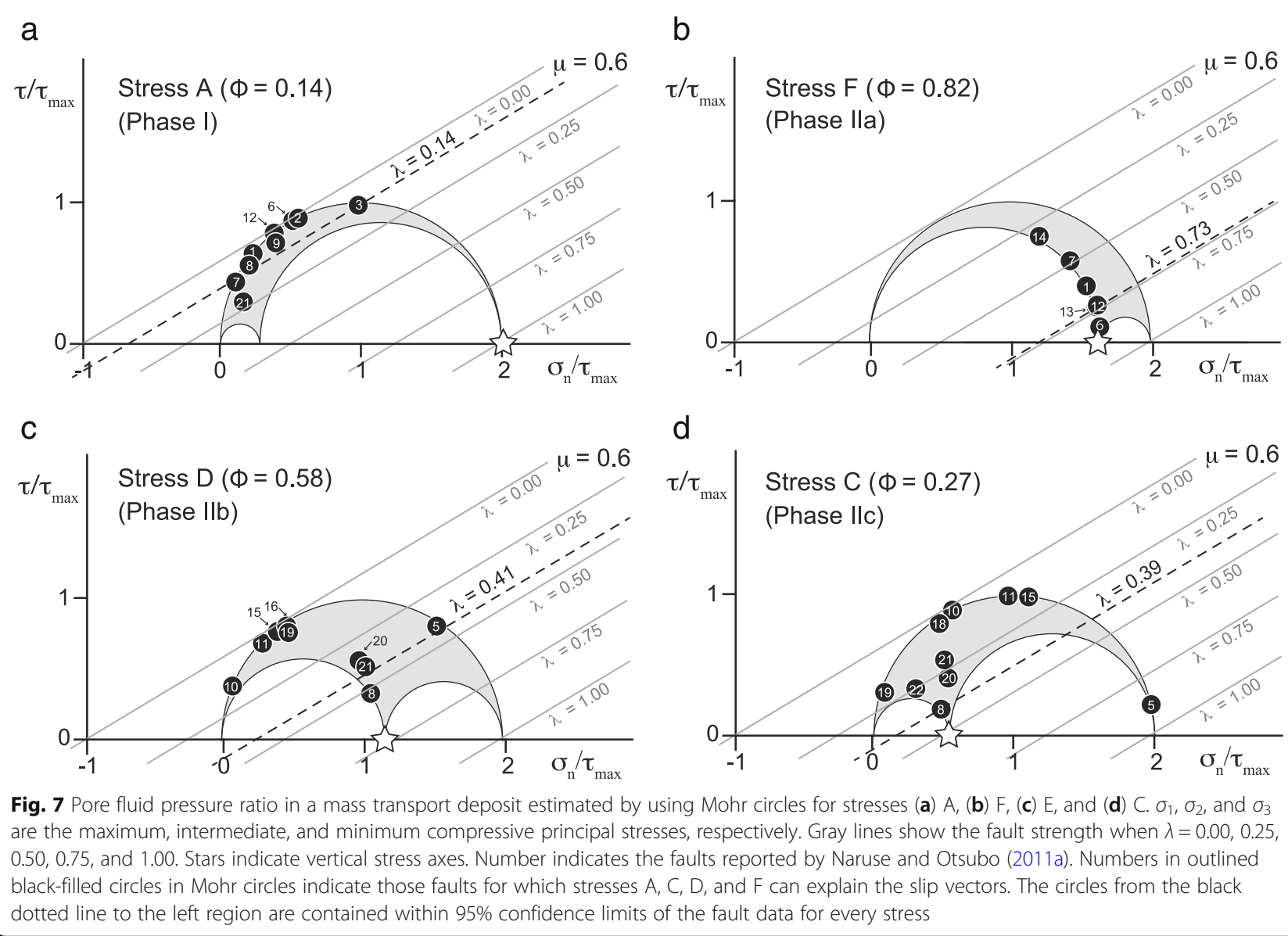


confidence limit for stress $\mathrm{C}$ and plots to the far right of the Mohr diagram (Fig. 7d). We can then calculate the pore fluid pressure coefficient for the MTDs from the Mohr diagrams.

\section{Discussion}

Here, we discuss temporal changes in the stress fields detected in the submarine MTD based on the outcropbased approach. The two groups of the stress fields detected from the internal structures of a submarine MTD in the Akkeshi Formation were interpreted to represent the two flow phases (phases I and II) during the evolution of the debris flow (Naruse and Otsubo 2011a, 2011b). Numerical simulations of debris flows revealed that the flow initially expands in the downstream region (Naruse and Otsubo 2011b), where the blocks in the flow undergo vertical compression and lateral extension during this flow phase (phase I). This phase I stress field, which indicates uniaxial vertical compression, is best represented by stress A. The head of the debris flow reaches the low-gradient downstream region and then decelerates rapidly after lateral expansion of the flow, whereas the main body of the flow continues to move. This results in the shortening of the slide body due to the velocity difference between the head and the body, which produces compressional ridges on the surface of the deposit (Naruse and Masuda 2006; Naruse and Otsubo 2011b). This phase II stress field, which indicates triaxial compression with the $\sigma_{1}$-axis oriented parallel to the horizontal flow direction (from northwest to southeast; Naruse and Otsubo 2011a), is best represented by stresses B-F (Naruse and Otsubo 2011a, 2011b). In this study, we ignore the rotation of block during the phase II because the orientation of $\sigma_{1}$-axis coincides with the paleo-current direction (Naruse and Otsubo 2011a).

The numerical experiments suggest that the maximum horizontal compressive stress $\left(\sigma_{\text {hmax }}\right)$ increases during phase II, when the debris flow is deposited on the basin plain (Naruse and Otsubo 2011b). This may cause a variation in the stress ratio $(\Phi)$, which is defined as:

$$
\Phi=\frac{\sigma_{2}-\sigma_{3}}{\sigma_{1}-\sigma_{3}}
$$

We therefore subdivided phase II into three subphases on the basis of the stress ratio: phases IIa, IIb, and IIc, which have high $(\Phi=\sim 0.8)$, intermediate $(\Phi=\sim 0.6)$, and low $(\Phi=\sim 0.3)$ stress ratios, respectively (Fig. 7). Phase IIa underwent an axial tension with $\sigma_{1} \approx \sigma_{2}\left(=\sigma_{v}\right)>\sigma_{3}$, where $\sigma_{v}$ is the overburden pressure, whereas phase IIc underwent an axial compression with $\sigma_{1}>\sigma_{2}\left(=\sigma_{\mathrm{v}}\right) \approx \sigma_{3}$. Therefore, the increase in $\Phi$ represents the increase in $\sigma_{\text {hmax }}$ during phase II. We interpreted that stresses F, D, and C must be the primary stresses of phases IIa, IIb, and IIc, respectively, to ensure a consistent relationship between $\sigma_{v}$ and $\sigma_{\mathrm{hmax}}$.

We estimated $\sigma_{\text {hmax }}$ in phase II normalized by the differential stress of phase I (stress A; $\sigma_{v}^{A}-\sigma_{\text {hmin }}^{A}$ ) (Fig. 8), where $\sigma_{\text {hmin }}$ is the minimum horizontal compressive stress. We observe that $\sigma_{v}$ is highest in phase I and then decreases by a factor of two during phase II, as inferred from the temporal changes in the basal normal stress that are revealed in Fig. 5 of Iverson (1997). Here, the direction of $\sigma_{\mathrm{hmin}}$ is approximately orthogonal to the MTD paleocurrent direction (Naruse and Otsubo 2011b). $\sigma_{\mathrm{hmax}}$ during phase IIc is estimated to be approximately four times larger than $\sigma_{\text {hmax }}$ during phase IIa (Fig. 8) when $\sigma_{\text {hmin }}$ is held constant relative to $\sigma_{v}$ and $\sigma_{\text {hmax }}$.

The estimated $\lambda$ in phase II is larger than that in phase I (Fig. 8), which indicates the important relationship between pore fluid pressure and faulting during phase II. $\lambda$ reaches a maximum value during phase IIa and then decreases to a stable value by phase IIb, whereas $\sigma_{\mathrm{hmax}}$ increases throughout phase II (Fig. 8). We interpret that the increased pore fluid pressure during phase IIa is reduced during the faulting in phases IIb and IIc. These temporal changes in the MTD pore fluid pressures are consistent with the temporal changes in the basal pore pressure revealed by Iverson (1997).

Figure 9 shows a schematic illustration of the dynamic processes during phase II of the submarine MTD

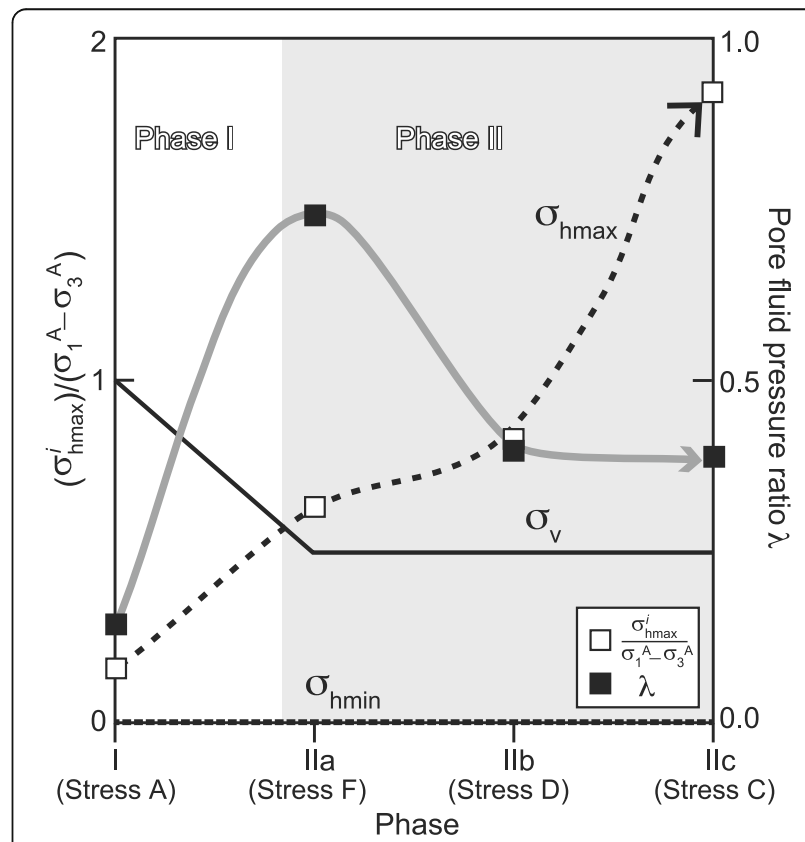

Fig. 8 Temporal changes in horizontal maximum compressional stresses and pore fluid pressure ratio in a MTD in the Akkeshi Formation. The horizontal axis shows the phases in the MTD. Left and right vertical axes show normalized $\sigma_{\text {hmax }}$ and $\lambda$, respectively 


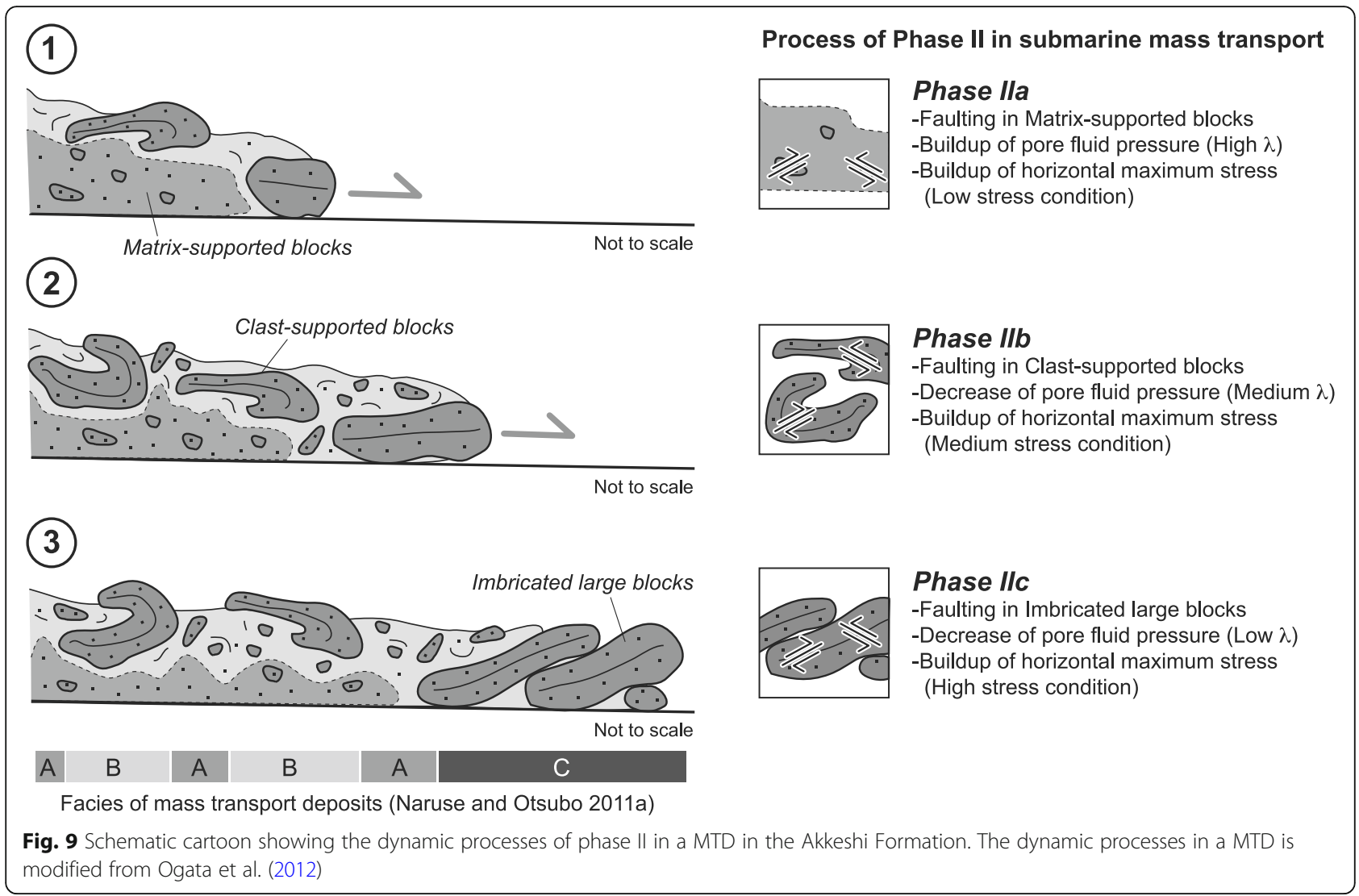

depositional sequence. We infer that the buildup of pore fluid pressure during phase IIa was caused by the rapid and undrained shortening deformation of the debris flow under matrix-supported conditions (Fig. 9a; Ogata et al. 2012, 2014a, 2014b). However, the decrease in pore fluid pressure caused an increase in the effective stress during the drained deformation of the debris flow following phase IIb, which resulted in the variable faulting patterns from phase IIa to phase IIc (Fig. 9b, c). These phenomena may have promoted shortening deformation of the debris flow during phase IIc (Fig. 9c), because faults 1822 (observed at the distal end of the outcrop) were activated by the phase IIc stress field (Fig. 9d). The above results therefore indicate that it is possible to estimate the temporal changes in the internal stresses and pore fluid pressures in MTDs from the relationships between the principal stress axes and the orientations of fault planes. Although the entire path of the flow may exceed tens of kilometers, this study implies that the $1.6 \mathrm{~km}$-long outcrop was large enough for examining sufficient number of blocks that can record the whole history of stress in the flow.

Our results suggest that a drop in pore fluid pressure plays a significant role in the deceleration and subsequent deposition of large-scale submarine debris flows (Ogata et al. 2012, 2014a, 2014b). This is the first known documented attempt to infer pore fluid pressures from outcropping submarine MTDs. Although previous studies have reported that the behavior of subaerial debris flows is controlled primarily by pore pressure (Iverson 1997, 2005), numerical modeling of submarine debris flows (e.g., Imran et al. 2001) generally assumes that the pore fluid pressure in such flows is constant, because they generally contain large amounts of clay particles that impede a drop in excess pore fluid pressure. However, the large-scale MTDs investigated here indicate the necessity to develop models that incorporate the process of pore fluid pressure. Future work will focus on comprehensive studies of the process by integration of the outcrop investigation and numerical study.

\section{Conclusions}

We examined temporal changes in the internal stresses and pore fluid pressures of a submarine mass transport deposit in the Akkeshi Formation from the central section of the Upper Cretaceous-Paleocene Nemuro Group, eastern Hokkaido Island, Japan. The evolution of this debris flow comprised of two phases: phase I consisted of radial spreading of the debris flow during downslope movement, and phase II consisted of compression during deposition on the basin plain. The distribution of fault orientations was sensitive to the internal stress phases, which can be 
attributed to the variable pore fluid pressure along the individual faults. There was a large increase in the pore fluid pressure ratio during the transition from phase I to phase II from the fault orientation distribution. Our analysis suggests that this drop in pore fluid pressure plays a significant role in the deceleration and subsequent deposition of large-scale submarine debris flows. The dynamics of submarine debris flow processes are poorly known, due to the extreme difficulties in directly observing them. The large-scale submarine mass transport deposit investigation here highlights the need to develop models that incorporate the dynamics of pore fluid pressure.

\section{Abbreviation}

MTD: Mass transport deposit

\section{Acknowledgements}

We thank Dr. Ogata and an anonymous reviewer for the improvement of the manuscript. We are also grateful to M. Utsunomiya and N. Yamaguchi for the helpful discussions. Some of the figures were drawn using the GMT software package (Wessel and Smith 1995).

\section{Funding}

This study was supported by MEXT KAKENHI (number 26109003).

\section{Availability of data and materials}

Please contact the author for data requests.

\section{Authors' contributions}

$\mathrm{MO}$ proposed the topic and conceived and designed the study. MO carried out the estimation of the internal pore pressure ratio, drafted the figures, and contributed to the assessment and discussion of the results. HN and AM contributed to the discussion of the results. All authors read and approved the final manuscript.

\section{Competing interests}

The authors declare that they have no competing interests.

\section{Publisher's Note}

Springer Nature remains neutral with regard to jurisdictional claims in published maps and institutional affiliations.

\section{Author details}

'Geological Survey of Japan, AIST, AIST Tsukuba Central 7, Higashi-1-1-1, Tsukuba, Ibaraki 305-8567, Japan. ${ }^{2}$ Division of Earth and Planetary Sciences, Kyoto University, Kitashirakawa Oiwakecho, Kyoto 606-8502, Japan.

Received: 29 March 2018 Accepted: 13 September 2018 Published online: 01 October 2018

\section{References}

Angelier J (1989) From orientation to magnitudes in paleostress determinations using fault slip data. J Struct Geol 11:37-50

Baroň I, Kernstocková M, Faridi M, Bubík M, Milovský R, Melichar R, Sabouri J, Babůrek J (2013) Paleostress analysis of a gigantic gravitational mass movement in active tectonic setting: the Qoshadagh slope failure, Ahar, NW Iran. Tectonophysics 605:70-87. https://doi.org/10.1016/S0040-1951(13)00569-6

Baroň I, Kernstockováb M, Melicharb R (2017) Stress field reconstruction in an active mudslide. Geomorphology. https://doi.org/10.1016/j.geomorph. 2017.04.020

Bott MHP (1959) The mechanics of oblique slip faulting. Geol Mag 96:109-117 Byerlee J (1978) Friction of rocks. Pure Appl Geophys 116:615-626

Canals M, Lastras G, Urgeles R, Casamor JL, Mienert J, Cattaneo A, De Batist M, Haflidason H, Imbo Y, Laberg JS, Locat J, Long D, Longva O, Masson DG, Sultan N, Trincardi F, Bryn P (2004) Slope failure dynamics and impacts from seafloor and shallow sub-seafloor geophysical data: case studies from the COSTA project. Mar Geol 213:9-72
D'Agostino V, Bettella F, Cesca M (2013) Basal shear stress of debris flow in the runout phase. Geomorphology 201:272-280

Festa A, Ogata K, Pini GA, Dilek Y, Alonso JL (2016) Origin and significance of olistostromes in the evolution of orogenic belts: a global synthesis. Gondwana Res 39:180-203

Gennesseaux M, Mauffret A, Pautot G (1980) Les glissements sous-marins de la pente continentale niçoise et la rupture de câbles en mer Ligure (Méditerranée occidentale). C R Acad Sci Paris 290:959-962

Harbitz CB, Løvholt F, Pedersen G, Masson DG (2006) Mechanisms of tsunami generation by submarine landslides: a short review. Norwegian J Geology Nor Geologisk Foren 86:255-264

Hubbert MK, Rubey WW (1959) Role of fluid pressure in mechanics of overthrust faulting. Bull Geol Soc Am 70:115-166

Husein S, Sudarno I, Pramumijoyo S, Karnawati D (2010) Paleostress analysis to interpret the landslide mechanism: a case study in Parangtritis, Yogyakarta. J Southeast Asian Appl Geology 2:104-109

Ilstad T, De Blasio FV, Elverhøi A, Harbitz CB, Engvik L, Longva O, Marr JG (2004a) On the frontal dynamics and morphology of submarine debris flow. Mar Geol 213:481-497

Ilstad T, Marr JG, Elverhoi A, Harbitz CB (2004b) Laboratory studies of subaqueous debris flows by measurements of pore-fluid pressure and total stress. Mar Geol 213:403-414

Imran J, Parker G, Locat J, Lee H (2001) 1D numerical model of muddy subaqueous and subaerial debris flow. J Hydraul Eng 127:959-968

Iverson RM (1997) The physics of debris flows. Rev Geophys 35:245-296

Iverson RM (2005) Debris-flow mechanics. In: Jakob M, Hungr O (eds) Debris-flow hazards and related phenomena. Springer, New York

Iverson RM, Reid ME, Logan M, LaHusen RG, Godt JW, Griswold JP (2011) Positive feedback and momentum growth during debris-flow entrainment of wet bed sediment. Nat Geosci 4:116

Jaeger J (1969) Elasticity fracture and flow, 3rd edn. Methuen \& Co. Ltd., London Jaeger JC, Cook NG (1979) Fundamentals of rock mechanics, 3rd edn. Chapman \& Hall, New York

Kiminami K (1978) Stratigraphic re-examination of the Nemuro Group. Chikyu Kagaku 32:120-132

Kiminami K (1983) Sedimentary history of the Late Cretaceous-Paleocene Nemuro Group, Hokkaido, Japan: a forearc basin of the Paleo-Kuril arc-trench system. J Geol Soc Jpn 89:607-624

Major JJ, Iverson RM (1999) Debris-flow deposition: effects of pore-fluid pressure and friction concentrated at flow margins. Geol Soc Am Bull 111:1424-1434

Morgan JK, Silver E, Camerlenghi A, Dugan B, Kirby S, Shipp C, Suyehiro K (2009) Addressing geohazards through ocean drilling. Sci Drilling 7:15-30. https:// doi.org/10.2204/iodp.sd.7.01.2009

Naruse H (2003) Cretaceous to Paleocene depositional history of North-Pacific subduction zone, reconstruction from the Nemuro Group, eastern Hokkaido, northern Japan. Cretac Res 24:55-71

Naruse H, Masuda F (2006) Visualization of the internal structure of the massive division in experimental sediment-gravity-flow deposits by mapping of grain fabric. J Sediment Res 76:854-865

Naruse H, Otsubo M (2011a) Heterogeneity of internal structures in a masstransport deposit, Upper Cretaceous to Paleocene Akkeshi Formation, Hokkaido Island, northern Japan. SEPM Spec Publ 96:279-290

Naruse H, Otsubo M (2011b) Internal stress fields of a large-scale submarine debris flow. In: Lykousis V, Sakellarious D, Locat J (eds) Submarine mass movements and their consequences. Springer, Heidelberg

Nemcok M, Lisle RJ (1995) A stress inversion procedure for polyphase fault/slip data sets. J Struct Geol 17:1445-1453

Nur A, Booker JR (1972) Aftershocks caused by pore fluid flow. Science 175:885-887

Ogata K, Mountjoy JJ, Pini GA, Festa A, Tinterri R (2014a) Shear zone liquefaction in mass transport deposit emplacement: a multi-scale integration of seismic reflection and outcrop data. Mar Geol 356:50-64

Ogata K, Mutt E, Pini GA, Tinterri R (2012) Mass transport-related stratal disruption within sedimentary mélanges: examples from the northern Apennines (Italy) and south-Central Pyrenees (Spain). Tectonophysics 568-569:185-199

Ogata K, Pogačnik Ž, Pini GA, Tunis G, Festa A, Camerlenghi A, Rebesco M (2014b) The carbonate mass transport deposits of the Paleogene Friuli Basin (Italy/Slovenia): internal anatomy and inferred genetic processes. Mar Geol 356:88-110

Otsubo M, Sato K, Yamaji A (2006) Computerized identification of stress tensors determined from heterogeneous fault-slip data by combining the multiple inverse method and K-means clustering. J Struct Geol 28:991-997 
Otsubo M, Yamaji A (2006) Improved resolution of the multiple inverse method by eliminating erroneous solutions. Comput Geosci 32:1221-1227

Rice JR (1992) Fault stress states, pore pressure distributions, and the weakness of the San Andreas Fault. In: Evans B, Wong TF (eds) Fault mechanics and transport properties of rock: a Festchrift in honor of W.F. Brace. Academic Press, London

Rickenmann D, Laigle DM, McArdell BW, Hübl J (2006) Comparison of 2D debrisflow simulation models with field events. Comput Geosci 10:241-264

Sibson RH (2007) An episode of fault-valve behavior during compressional inversion? The 2004 M(J) 6.8 mid-Niigata Prefecture, Japan, earthquake sequence. Earth Planetary Sci Lett 257:188-199

Terakawa T, Zoporowski A, Galvan B, Miller SA (2010) High-pressure fluid at hypocentral depths in the L'Aquila region inferred from earthquake focal mechanisms. Geology 38:995-998

Terzaghi K, Peck RB (1967) Soil mechanics in engineering practice. Wiley, New York

Wallace RE (1951) Geometry of shearing stress and relationship to faulting. J Geol 59:111-130

Ward SN (2001) Landslide tsunami. J Geophys Res 106:11201-11215

Wessel P, Smith WHF (1995) Free software helps map and display data. Eos Trans Am Geophysical Union 72:445-446

Yamaji A (2000) The multiple inverse method: a new technique to separate stresses from heterogeneous fault-slip data. J Struct Geol 22:441-452

Yamaji A, Otsubo M, Sato K (2006) Paleostress analysis using the Hough transform for separating stresses from heterogeneous fault-slip data. J Struct Geol 28:980-990

\section{Submit your manuscript to a SpringerOpen ${ }^{\circ}$ journal and benefit from:}

- Convenient online submission

- Rigorous peer review

- Open access: articles freely available online

High visibility within the field

- Retaining the copyright to your article

Submit your next manuscript at $\boldsymbol{\nabla}$ springeropen.com 